\title{
Extreme chromosomal heterogeneity in a small-island population of Rumex acetosa
}

\author{
J. S. Parker and \\ A. S. Wilby
}

School of Biological Sciences, Queen Mary College, Mile End Road, London E1 4NS

\begin{abstract}
Chromosome analyses of 227 mature plants of the dioecious species Rumex acetosa collected on the small island of Skomer have revealed an extremely high level of unique and polymorphic variation. The three common polymorphisms in this species_-supernumerary segments on chromosomes 1 and 6, and B-chromosomes-are widespread on the island and the frequency of supernumerary segment 1 is higher than in all 37 mainland populations previously studied. Novel variants, unknown elsewhere, occur in each polymorphism. Fourteen different chromosome rearrangements are unique to the island, and eleven of these were detected in 67 plants from a small area which had undergone a population crash in 1977. It is argued that the genome of $\boldsymbol{R}$. acetos $a$ is undergoing rapid reorganisation on this small island which may be associated with an enforced shift towards inbreeding in this dioecious species.
\end{abstract}

\section{INTRODUCTION}

Comparisons of the genetic structure of mainland and island populations have given insights into many micro-evolutionary processes. Since island populations are likely to have arisen from a limited number of founders (Mayr, 1954) then the expectation is that these populations should be more homogeneous than those on the adjacent mainland with a reduction in average heterozygosity and number of alleles per locus (Nei et al., 1975). Studies of some species support this contention (Ayala et al., 1971; Glover and Barrett, 1987) although in others there are no differences between island and mainland populations in allele number or average heterozygosity as assessed from isozyme studies, even where morphological differentiation is evident. Such is the case in the mouse populations of the islands around the coasts of Britain (Berry and Murphy, 1970).

Few comparative genetic studies of island and mainland populations of flowering plants have been made (Glover and Barrett, 1987) and there are no reports of chromosomal comparisons comparable to those involving the inversion systems in Drosophila. The dioecious flowering plant Rumex acetosa is a suitable species for a chromosomal study because of its extreme cytological heterogeneity. In British mainland populations, the $\mathrm{Y}$-chromosomes of the males show such varia- bility in structure that on average every other male is identifiable (Wilby and Parker, 1986, 1987). In addition, there are three widespread polymorphisms (Wilby and Parker, 1988), and novel structural rearrangements are generated with a frequency of about 1 in 50 individuals per generation (Wilby, 1987). Thus there is sufficient diversity of karyotypes, particularly in males, to allow comparisons of cytological structure in mainland and island populations to be made.

The cytological structure of populations of $R$. acetosa on the small island of Skomer which lies off the coast of the Welsh county of Dyfed are reported here. $R$. acetosa is abundant on this island, occupying a variety of habitats. As well as affording a comparison with mainland populations, the island provides an opportunity to examine the effects of a recent bottleneck: the population of a part of the island crashed in 1977 and recolonisation of this area from a known small group of survivors is under way.

Chromosome studies of mature population plants have revealed a remarkable level of chromosome variation on Skomer. Fourteen different chromosome rearrangements all of which are unknown on the mainland of Britain have been detected in only 227 plants from this small island and the great majority of these are localised in the area which experienced the population crash. The genome of $R$. acetosa is apparently undergoing 
rapid reorganisation in this area and this may be linked with an enforced change in breeding behaviour in this normally outbreeding dioecious plant.

\section{THE ISLAND AND THE COLLECTIONS}

Skomer Island is located at the southern end of St. Bride's Bay, Dyfed, Wales (SM 725095). It is about $2.5 \mathrm{~km}$ long by $1.5 \mathrm{~km}$ wide, with an area of about 290 hectares, and is mainly a plateau about 60 metres above sea level. The island is uncultivated and the vegetation consists of short rabbit-grazed turf or Pteridium-dominated areas within which $R$. acetosa is frequent. On the periphery of the island, soil disturbance in the vicinity of rabbit burrows allows large almost pure stands of $R$. acetosa to develop.

Seven collections of mature plants were made (fig. 1). The Farm Field (FF) and South Valley (SV) samples were from Pteridium-dominated areas, the Wick Stream (WS) from dense shortgrazed turf, and the two Garland Stone samples (GST and GSQ) from rabbit-disturbed areas. About 30 plants were collected from each area at 0.5 metre intervals along a transect while 47 plants were sampled from within a small quadrat $1.5 \mathrm{~m} \times 0.4 \mathrm{~m}$ (GSQ) situated three metres from the Garland Stone transect (GST).

Particular attention was given to the cliff-top at the exposed western end of the island because of the recent history of the vegetation in this area. A rabbit-exclosure $30 \times 30$ metres in extent was erected in 1973 within which a dense mat of Festuca developed and throughout which $R$. acetosa was scattered. Following flooding and drought in the mid-1970s an area of about one hectare around the exclosure was completely denuded of vegetation by 1977 . Recolonisation by seed of $R$. acetosa

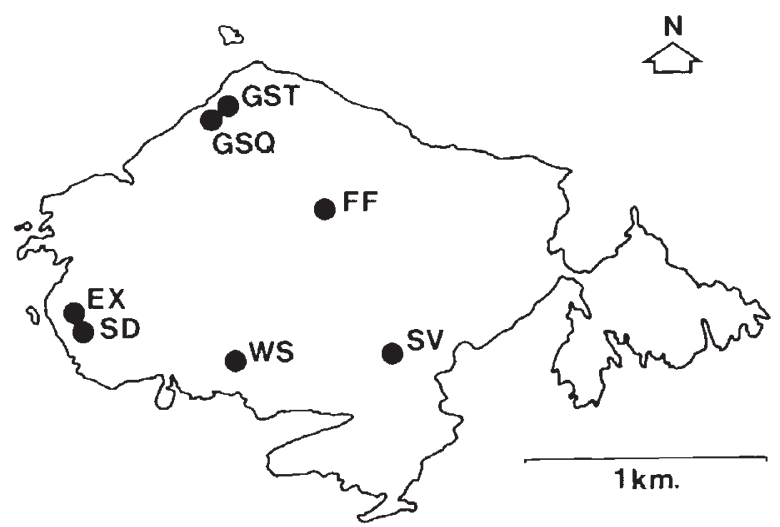

Figure 1 Map of Skomer Island showing collection sites. has subsequently taken place within 15 metres of the exclosure from the small group of survivors within the exclosure. Samples from inside (Exclosure, EX) and outside (Skomer Head, SD) have been taken, consisting of 30 and 37 plants respectively.

The five areas of the island which have been examined are situated at distances from $0.7 \mathrm{~km}$ to $1 \cdot 3 \mathrm{~km}$ apart (fig. 1 ).

\section{THE CHROMOSOME CONSTITUTION OF RUMEX ACETOSA}

Female plants of $R$. acetosa have the chromosome constitution $2 n=12+\mathrm{XX}$ while males have $2 n=$ $12+X Y^{1} Y^{2}$. The six autosome pairs are acrocentric and distinguishable in good preparations (fig. 2). The $\mathrm{X}$ is a metacentric 50 per cent larger than the largest autosome while the Ys are 83 and 74 per cent the length of the $X$ respectively. $Y$ centromeres can be located at any point within the central 40 per cent of the chromosome (Wilby and Parker, 1986).

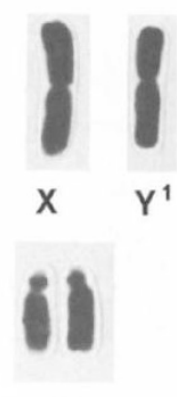

3
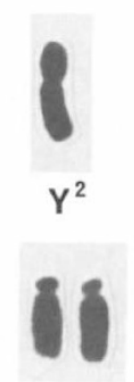

4

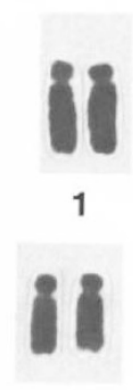

5

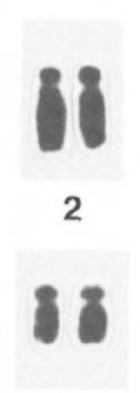

6
Figure 2 Chromosome complement of male Rumex acetosa $\times 2,500$.

Three widespread polymorphisms are found in $R$. acetosa. Small telocentric B-chromosomes are frequently encountered. They are unstable and vary in number between cells, tissues and organs so an exact estimate of frequency cannot be made. In addition heterochromatic supernumerary segments are found on the short arms of chromosomes 1 and 6 (figs. 3 and 4). On mainland Britain SS1 is a low-frequency polymorphism while SS6 reaches higher proportions in populations (Wilby and Parker, 1988).

\section{RESULTS}

Chromosome analyses have been carried out on 227 mature plants from Skomer, of which 71 were 
male. These observations have revealed extensive Y-variation, the three common widespread polymorphisms, and a remarkably high frequency of chromosome variants limited to the island.

\section{(i) Y-chromosome variability}

The number of Y-variants per sample on this small island is as high as on the mainland (Wilby and Parker, 1987) with an average of six variants in a ten-male sample. In total, $43 \mathrm{Y}$-variants were found in the 71 males, of which 14 variants were limited to single populations. Most variants occurred only once in a sample but within the Garland Stone quadrat (GSQ) a single Y-morph was identified seven times in 14 males. Even in this tiny area of only $0.6 \mathrm{~m}^{2}$, however, five Y-variants were found, emphasising the remarkable heterogeneity of $\mathrm{Y}$ variation.

Despite the high level of unique variants per population a few of the Y-variants are widespread. For example, a variant with both Ys acrocentric $\left(a^{+} a^{+}\right.$in the terminology of Wilby and Parker, 1986) occurs in six of the seven samples. If pairwise comparisons of populations are made, however, most have only the widespread $a^{+} a^{+}$variant in common and no pair of populations shares more than three Y-morphs (table 1).
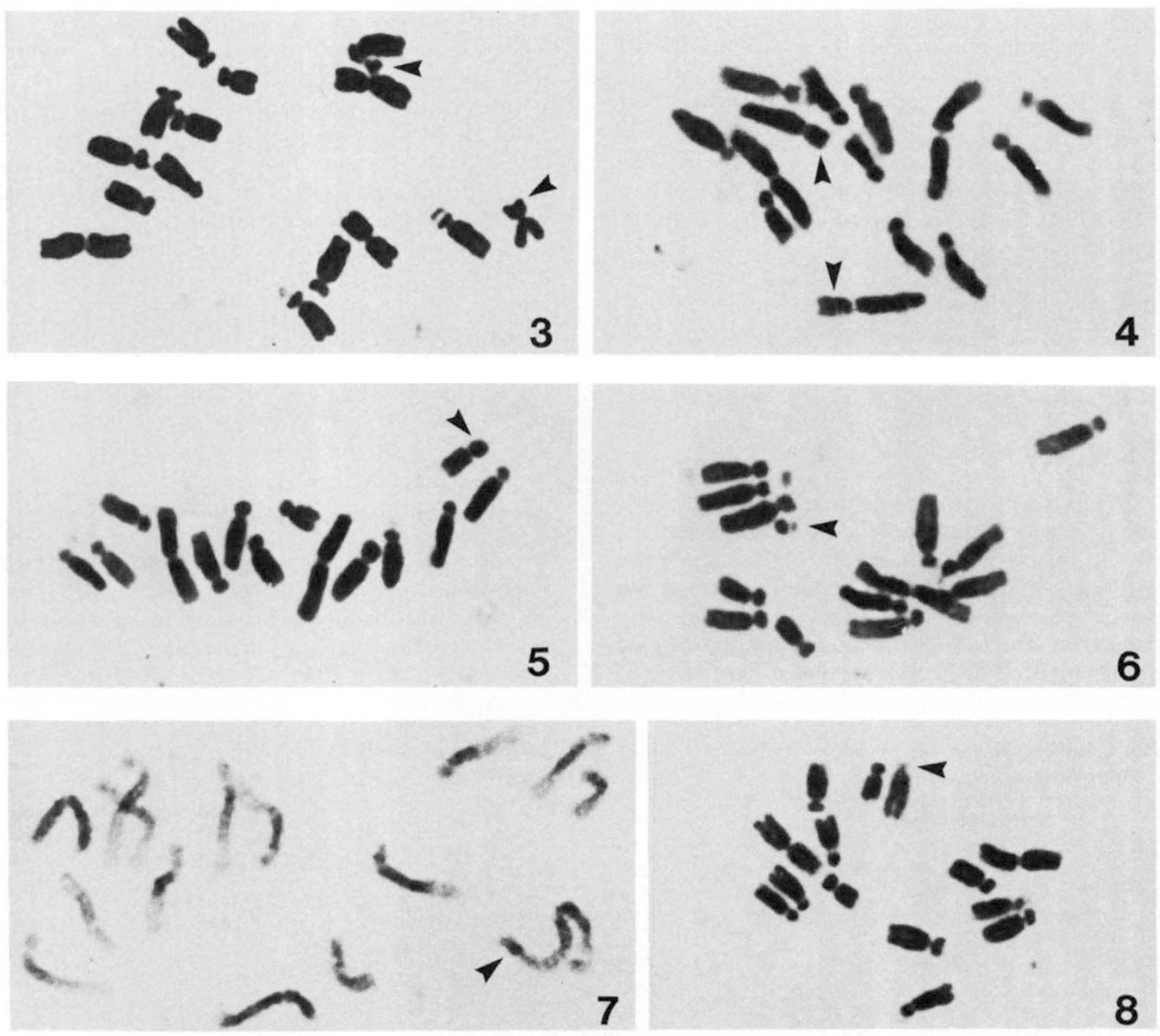

Figure 3. Supernumerary segment 6 heterozygote with a single telocentric B-chromosome (segment and B arrowed). Figs. 3-8 $\times 2025$. Figure 4. Plant carrying one standard and one large supernumerary segment on chromosome 1 (arrowed). Figure 5 . Small variant of supernumerary segment 6 (arrowed). Figure 6. Acrocentric B-chromosome (part cell; B arrowed). Figure 7. $\mathrm{X}$-chromosome variant with interstitial heterochromatic block at mitotic prophase (arrowed). Figure 8. Centric shift in. chromosome 2 (arrowed). 
Table 1 Comparison of the Skomer populations of Rumex acetosa showing the number of $\mathrm{Y}$-variants common to pairs of populations. Figures in brackets indicate the number of Y-variants and total males examined

\begin{tabular}{lllllll}
\hline & EX & GSQ & GST & SV & FF & WS \\
\hline SD $(4 / 8)$ & 1 & 2 & 1 & 2 & 3 & 1 \\
EX $(9 / 12)$ & & 2 & 0 & 2 & 3 & 1 \\
GSQ $(5 / 14)$ & & & 1 & 3 & 3 & 1 \\
GST $(5 / 5)$ & & & & 1 & 2 & 0 \\
SV $(9 / 16)$ & & & & & 3 & 1 \\
FF $(6 / 10)$ & & & & & & 1 \\
WS $(5 / 6)$ & & & & & &
\end{tabular}

The polymorphic segments on chromosomes 1 and 6 (SS1 and SS6), widespread on the mainland, are both found on Skomer. The chromosome frequency of SS1 ranges from 0.08 (SV) to 0.25 (EX), an average frequency of $0 \cdot 15$ (table 2). The frequency of SS1 in the Exclosure is higher than in any of the 37 mature or seed-grown populations from the mainland so far studied (Wilby and Parker, 1988). Interestingly, the highest mainland frequency $(0.20)$ has been found at Tintagel, Cornwall, on a west-facing coastal heathland similar in environment to western Skomer.

The SS1 chromosome is morphologicallyconstant on the mainland and only one variant chromosome-with a small deletion-was been found. On Skomer, however, a novel SS1 occurs in two Exclosure plants and three from the adjacent Skomer Head plants, suggesting that the variant arose in this area. The segment is about twice the standard size (fig. 4) and all the additional material is heterochromatic. This variant has presumably arisen from the SS1 by unequal crossing-over or another method of heterochromatin "growth".
Sixty-five of the 227 Skomer plants carried SS1 but only two were homozygotes (table 2). The expectation with this chromosome frequency is 4.9 and thus a slight deficiency of homozygotes is indicated although much larger sample sizes are required to establish this.

By contrast, SS6 is at a very low frequency with only 20 heterozygotes detected (table 2 ). However, all seven samples contained SS6 although the average chromosome frequency was only $0 \cdot 044$. Mainland populations carry SS6 at an average frequency about twice this. Thus the mainland pattern of segment frequencies-SS6 more abundant than $\mathrm{SS} 1$-is reversed on Skomer.

A novel SS6 chromosome occurs on Skomer, the only variant of this segment so far detected. This is a deletion-morph with about half the standard amount of heterochromatin (fig. 5). Seven plants with this variant have been found spread amongst five populations across the island. The origin of the variant segment may thus have been early in the colonisation of the island such that equilibrium has not been reached.

B-chromosomes have been detected in all samples and in 28 of the 227 plants. They are mainly of the standard telocentric type found widely on the mainland. In three plants from Skomer Head, however, an acrocentric B has been found (fig. 6). Thus each of the three widespread polymorphisms have chromosome variants which appear to be unique to this small island.

\section{(ii) Other chromosome variants}

In addition to the three variants of the common polymorphisms, a further eleven structural changes affecting the $\mathrm{X}$-chromosome and the autosomes have been detected in the island populations (table 3).

Table 2 Frequencies of supernumerary segments 1 and 6 (SS1 and SS6) and B-chromosomes in seven mature-plant samples of Rumex acetosa from Skomer

\begin{tabular}{|c|c|c|c|c|c|c|c|c|c|}
\hline \multirow[b]{3}{*}{ Population } & \multicolumn{9}{|c|}{ Polymorphic variants } \\
\hline & \multirow[b]{2}{*}{$+t$} & \multirow{2}{*}{$\begin{array}{l}\text { SS1 } \\
+\mathrm{S}\end{array}$} & \multirow[b]{2}{*}{ SS } & \multirow{2}{*}{$\begin{array}{l}\text { SS1 } \\
\text { Freq }\end{array}$} & \multicolumn{2}{|c|}{ SS6 } & \multirow{2}{*}{$\begin{array}{l}\text { SS6 } \\
\text { Freq }\end{array}$} & \multicolumn{2}{|c|}{ B-chrs. } \\
\hline & & & & & ++ & $+\mathrm{S}$ & & $0 \mathrm{~B}$ & $+\mathrm{B}$ \\
\hline EX & 13 & 13 & 0 & $0 \cdot 250$ & 25 & 1 & $0 \cdot 019$ & 24 & 2 \\
\hline $\mathrm{SD}$ & 21 & 16 & 0 & $0 \cdot 216$ & 33 & 4 & 0.054 & 32 & 5 \\
\hline GSQ & 38 & 8 & 1 & $0 \cdot 106$ & 43 & 4 & 0.043 & 38 & 9 \\
\hline GST & 20 & 9 & 0 & $0 \cdot 155$ & 27 & 2 & $0 \cdot 034$ & 28 & 1 \\
\hline WS & 22 & 7 & 0 & $0 \cdot 121$ & 27 & 2 & 0.034 & 27 & 2 \\
\hline $\mathrm{FF}$ & 23 & 5 & 1 & $0 \cdot 121$ & 26 & 3 & 0.052 & 22 & 7 \\
\hline SV & 25 & 5 & 0 & 0.083 & 26 & 4 & 0.067 & 25 & 5 \\
\hline Totals & 162 & 63 & 2 & $0 \cdot 148$ & 207 & 20 & 0.044 & 196 & 31 \\
\hline
\end{tabular}


Table 3 The numbers of plants carrying novel chromosome variants in 227 plants of Rumex acetosa from Skomer. The chromosomes involved are given in brackets

\begin{tabular}{|c|c|c|c|c|c|c|c|}
\hline \multicolumn{3}{|c|}{ X-chromosome } & \multicolumn{4}{|c|}{ Autosomes } & \multirow[b]{2}{*}{ Del. } \\
\hline$X+$ het. & $\begin{array}{l}\text { Centric } \\
\text { shift }\end{array}$ & $\mathrm{X} / \mathrm{A}$ & $\begin{array}{l}\text { Large } \\
\text { SS1 }\end{array}$ & $\begin{array}{l}\text { Small } \\
\text { SS6 }\end{array}$ & $\begin{array}{l}\text { Centric } \\
\text { shift }\end{array}$ & $\begin{array}{l}\text { A/A } \\
\text { int. }\end{array}$ & \\
\hline 11 & 1 & $\begin{array}{l}3 \\
(X / 2)\end{array}$ & 5 & 7 & $\begin{array}{l}1(1) \\
2(2) \\
2,1(3) \\
5(6)\end{array}$ & $\begin{array}{l}3(3 / 6) \\
1(4 / 5)\end{array}$ & $\begin{array}{l}1 \\
(6)\end{array}$ \\
\hline
\end{tabular}

$\mathrm{X}+$ het $=\mathrm{X}$ chromosome with additional heterochromatic segment; $\mathrm{X} / \mathrm{A}=\mathrm{X} /$ Autosome interchange; $\mathrm{A} / \mathrm{A}=$ autosome/autosome interchange;

Del. = deletion.

\section{(a) Heterochromatin in the X-chromosome}

The X-chromosome of $R$. acetosa is usually completely euchromatic but 11 of the 67 plants in the Skomer Head and Exclosure samples carried an $\mathrm{X}$ with a heterochromatic segment. This variant $\mathrm{X}$ is slightly acrocentric and larger than the standard $\mathrm{X}$ due to a block of heterochromatin very near the end of one arm (fig. 7). The simplest method of generating such a variant is by $\mathrm{X} / \mathrm{Y}$ interchange, with one break in the arm of a Y adjacent to the pairing segment and the X-break through the pairing segment itself. An alternative origin, requiring three breaks, is by insertion of a Y-segment or supernumerary segment fragment into an $\mathrm{X}$.

\section{(b) Centric shifts}

Single centric shifts in chromosomes $X, 1,2$ and 6 and two in chromosome 3 have been detected (figs. 8 and 9). The variant chromosomes were

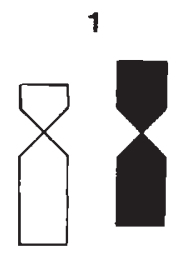

SD 35

6

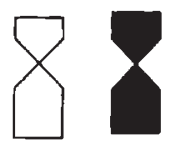

SD10,37 F F 24, 28 SV 22
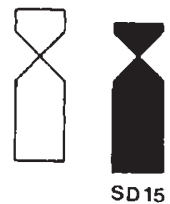

$$
\begin{aligned}
& \text { SD } 15 \\
& \text { SD10 }
\end{aligned}
$$
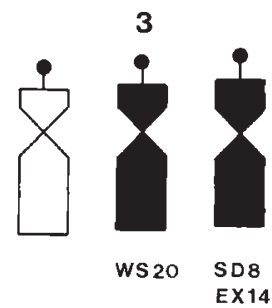

$\mathrm{X}$

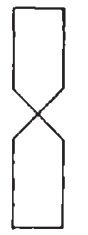

SD 4
Figure 9 Centric shifts found in populations on Skomer Island; population origins indicated. carried by 12 plants in five populations with that in six found in different parts of the island-populations $\mathrm{FF}, \mathrm{SD}$ and $\mathrm{SV}$-suggesting that it has reached low-frequency polymorphism proportions. The others, however, were limited to single areas with four in the Skomer Head/Exclosure region and one at Wick Stream.

Three different interchanges have been found, two in plants from the Garland Stone samples and one in a plant from the Exclosure. Two are wholearm exchanges (autosomes $4 / 5$ and 3/6) while the third, an X/2 exchange, has break points in interstitial locations (fig. 10).
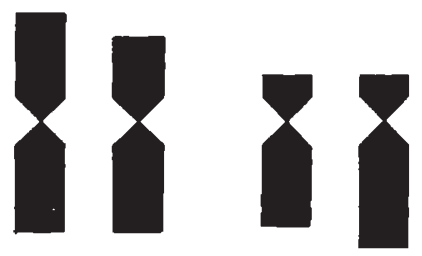

GST 26
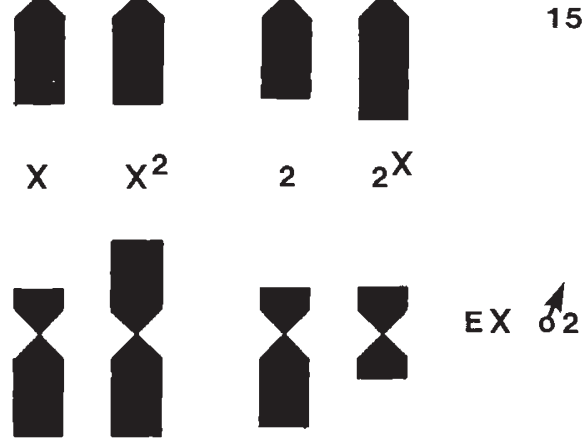

$x^{2}$
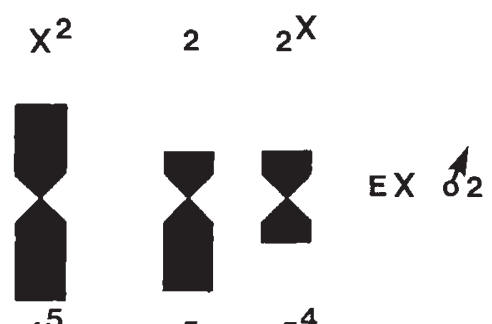

4
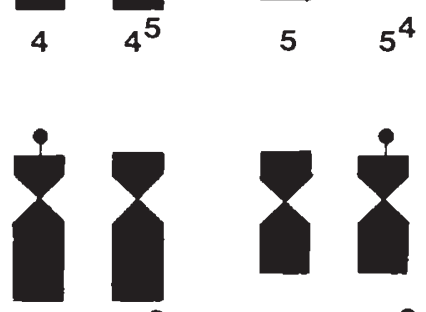

GS 14 26

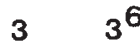

$66^{3}$

Figure 10 Interchanges found in populations on Skomer Island; population origins indicated. 


\section{(c) A deletion of chromosome 6}

A single plant of the Skomer Head sample was monosomic for the short arm of chromosome 6 . It is remarkable that this plant, of normal size, reached maturity with such a large deletion, particularly under the rigorous conditions encountered in natural populations. Only one other deletion has been found in this species and this affected the long arm of chromosome 6 . This plant from a seed sample grew very slowly and died before flowering.

\section{(d) Karyotype heterogeneity in populations}

The extremely high level of karyotype heterogeneity in the Skomer samples can be illustrated by considering the number of recognisably-distinct chromosome complements in the samples. Even if we exclude the extreme variation due to Y-chromosomes then the number of karyotypes ranges from a minimum of 11 in 47 plants in the Garland Stone quadrat to 18 karyotypes in 37 plants at Skomer Head.

\section{DISCUSSION}

\section{(i) Y-chromosome hypervariability}

The pattern of Y-chromosome variability described in $R$. acetosa showed that, on average, every second male in a population was identifiable, that all populations have distinctive patterns of Y-variation, and that large and small populations are equally variable (Wilby and Parker, 1986, 1987). The number of $Y$-variants detected on the small island of Skomer is as high as on the mainland. This is remarkable since it would be expected that small island populations should be descended from a relatively small number of colonisers, the Founder Principle of Mayr (1954). The massive Y-variation on Skomer presumably depends on the high rate of mutation; controlled crosses indicate a rate of 1 in $80 \mathrm{Y}$ chromosomes per generation for centromere relocation (Wilby, 1987).

At the small distances between samples on Skomer it is possible to trace some similarities in Y-constitution between populations. No pairs of samples, however, hold more than three variants in common. Even the Exclosure and Skomer Head samples are no more similar than any other pair despite the fact that the two areas abut and that the parents of the Skomer Head recoloniser plants were located within the Exclosure.

\section{(ii) The level of karyotype heterogeneity}

In natural populations it is supposed that between 1 in 200 and 1 in 500 individuals carry a unique chromosome rearrangement (White, 1973; Hewitt, 1979). This figure may well be too low by an order of magnitude, at least in some species such as the liliaceous plant Scilla autumnalis (Parker et al., 1985). In $R$. acetosa plants grown from wildcollected seeds about 1 in 50 carry a novel structural rearrangement. Thus $R$. acetosa appears to have a very high rate of spontaneous chromosome mutation. Even this rate, however, seems low when we consider the cytological structure of the mature populations of the very small island of Skomer: 14 chromosome variants limited to the island in only 227 plants. These rearrangements affect both the widespread polymorphisms found commonly in this species-supernumerary segments and Bchromosomes-and the standard complement. Six variants were detected once only and represent non-polymorphic variation while four rearrangements were detected in five or more plants and can be considered as reaching polymorphic proportions. Two of these polymorphisms--the large SS1 and the $\mathrm{X}$-chromosome with a heterochromatic block-were limited to plants around Skomer Head while the SS6 variant and the centric shift on six were more scattered over the island, in five and three samples respectively.

The enhanced level of chromosome variation on Skomer is strikingly and non-uniformly distributed, with the vast majority detected in the 67 plants from Skomer Head and the Exclosure. In this small area 11 of the 14 variants were detected and eight of them were exclusive to this region. By contrast, no more than two variants were found in any other population. Thus although the level of chromosome variation on Skomer is enhanced over general levels for this species, at the extreme western end of the island the whole genome is apparently undergoing rapid reorganisation. This is particularly striking amongst the 37 Skomer Head recolonising plants which carry four variants not shared by the presumptive parental population within the adjacent Exclosure. The close relatedness of these two samples is emphasised, however, by four variants held in common.

What can account, then, for this genomic revolution? A possible explanation may be relaxation of selection pressures associated with reduced competition in recoloniser, and thus rapidlyexpanding, populations. One of the most convincing, and indeed one of the earliest, reports of this relationship is in the butterfly Melitaea aurinea 
which showed a dramatic rise in wing-pattern variants with explosive population increase (Ford, 1964). This explanation is inadequate to explain the present observations for two reasons. Firstly, while the Skomer Head sample is indeed recolonising, the Exclosure sample is drawn from a wellestablished mature population, and both show an extremely high frequency of variants. Secondly, the level of chromosome variation displayed by the Skomer Head plants should be of similar magnitude to that in unselected seed samples. It is in fact far higher.

The population of $R$. acetosa in the Skomer Head region has undergone a severe bottleneck in the last 10 years. The number of plants in this area must have dropped from many thousands to about 100 or even fewer remaining isolated within the Exclosure. The effective population size of the Exclosure plants must also have crashed with the abolition of seed and particularly pollen inflow even if the actual death of mature plants was minimal. Thus the survivors will have undergone an enforced shift in breeding behaviour towards inbreeding. The effects of inbreeding a normallyoutbreeding species are recognisable in the external phenotype by a decline in vigour and fertility, and the chromosomes also respond. In rye, for example, inbred lines show reduced chiasma frequencies but increased between- bivalent and PMC variances. In addition the rate of spontaneous breakage and reunion increases in some lines (Rees, 1961; Jones, 1969). This has also been demonstrated in the grasshopper Pyrgomorpha kraussii in which meiotic collapse attendant upon inbreeding was accompanied by a burst of structural rearrangements in the germ-line (Lewis and John, 1959). There is an absence of observations of such inbreeding-associated increases in chromosome mutation rates in natural populations but the experimental evidence suggests that this should occur. In $R$. acetosa, if inbreeding is associated with this genomic revolution, then we have the intriguing possibility of reduced overall heterozygosity at the genic level accompanying massive heterogeneity at the chromosome level.

Recently Walbot and Cullis (1985) have reviewed the case for rapid genomic changes in plants. They propose that the plant genome is in a state of flux with changes in the molecular architecture a standard feature of growth and development. Interestingly, a common theme linking the examples they give is that stress conditions are involved. This stress may be internal, and has been categorised as the "stressful genome" by McClintock (1978). In maize, the transposable ele- ment family Ac/Ds acts as a focus for continuing chromosome instabilities on the chromosome into which they are inserted. Similarly in Drosophila random insertion of the transposable elements of the I-R and P-M hybrid dysgenesis systems lead to rearrangements affecting all chromosomes of the complement (Bregliano and Kidwell, 1983; Engels and Preston, 1984). In this present paper rapid reorganisation affecting the whole genome is reported. Perhaps we have identified here a group of plants in which the genome has become unstable as a result of either external or internal stress. The chromosomal rearrangements are clearly transmissible and such populations may act as foci for chromosome evolution.

Acknowledgements We wish to thank the Nature Conservancy and the West Wales Trust for Nature Conservation for allowing us to work on Skomer. The help of Stephen Sutcliffe, Warden, is much appreciated. A. S. Wilby acknowledges the support of an SERC research studentship.

\section{REFERENCES}

AYALA, F. J., POWELL, J. R, AND DOBZHANSKY, T. 1971. Enzyme variability in the Drosophila willistoni group. II. Polymorphisms in continental and island populations of Drosophila willistoni. Proc. Natl. Acad. Sci., USA, 68, 24802483.

BERRY, R. J. AND MURPHY, H. M. 1970. The biochemical genetics of an island population of the house mouse. Proc. Roy. Soc. B, 176, 87-103.

BREGLIANO, J. C. AND K1DWELL, M. G. 1983. Hybrid dysgenesis determinants. In Shapiro, J. A. (ed.), Mobile Genetic Elements. Academic Press, New York.

ENGELS, W. R. AND PRESTON, C. R. 1984. Formation of chromosome rearrangements by P-factors in Drosophila. Genetics, 107, 657-678.

FORD, E. B. 1964. Ecological Genetics, Methuen \& Co., London.

GLOVER, F. AND BARRETT, S. C. H. 1987. Genetic variation in continental and island populations of Eichhornia paniculata (Pontederiaceae). Heredity, 59, 7-18.

HEWITT, G. M. 1979. Orthoptera. In John, B. (ed.), Animal Cytogenetics. Gebruder Borntraeger, Berlin.

JONES, G. H. 1969. Further correlations between chiasmata and U-type exchanges in rye meiosis. Chromosoma, 26, 105118.

LEW1S, K. R. AND JOHN, B. 1959. Breakdown and restoration of chromosome stability following inbreeding in a locust. Chromosoma, 10, 589-618.

McCLINTOCK, B. 1978. Mechanisms that rapidly reorganise the genome. Stadler Symposium, 10, 25-48.

MAYR, E. 1954. In Huxley, J., Hardy, A. C. and Ford, E. B. (eds) Evolution as a Process, Allen and Unwin, London.

NEI, M., MARUYAMA, T. AND CHAKRABORTY, R. 1975. The bottleneck effect and genetic variability in populations. Evolution, 29, 1-10. 
PARKER, J. S., TAYLOR, S. AND WILBY, A. S. 1985. Plant populations and chromosome variation. J. Agric. Soc., 65, 109-130.

REES, H. 1961. Genotypic control of chromosome form and behaviour. Bot. Rev., 27, 288-318.

WALBOT, V. AND CULLIS, C. 1985. Rapid genomic change in higher plants. Ann. Rev. Pl. Physiol., 36, 367-396.

White, M. J. D. 1973. Animal Cytology and Evolution. C.U.P., Cambridge.
WII.BY, A. S. AND PARKER, J. S. 1986. Continuous variation in Y-chromosome structure of Rumex acetosa. Heredity, 57, $247-254$

WILBY, A. S. AND PARKER, J. S. 1987. Population structure of hypervariable Y-chromosomes in Rumex acetosa. Heredity, 59, 135-143.

WII.BY, A. S. AND PARKER, J. S. 1988. The supernumerary segment systems of Rumex acetosa. Heredity, 60, 109-117. 